\title{
INITIAL BOUNDS FOR ANALYTIC AND BI-UNIVALENT FUNCTIONS BY MEANS OF CHEBYSHEV POLYNOMIALS
}

\author{
Serap Bulut, Nanjundan Magesh and Vittalrao Kupparao Balaji
}

Abstract. In this paper, we obtain initial coefficient bounds for functions belong to a subclass of bi-univalent functions by using the Chebyshev polynomials and also we find Fekete-Szegö inequalities for this class.

Mathematics subject classification (2010): 30C45.

Keywords and phrases: Analytic functions, bi-univalent functions, coefficient bounds, Chebyshev polynomial, Fekete-Szegö problem, subordination.

\section{REFERENCES}

[1] R. M. Ali, S. K. LeE, V. Ravichandran And S. Supramanian, Coefficient estimates for biunivalent Ma-Minda starlike and convex functions, Appl. Math. Lett. 25, 3 (2012), 344-351.

[2] Ş. Altinkaya And S. Yalçın, Chebyshev polynomial coefficient bounds for a subclass of biunivalent functions, arXiv:1605.08224v1.

[3] S. Bulut, Coefficient estimates for a class of analytic and bi-univalent functions, Novi Sad J. Math. 43, 2 (2013), 59-65.

[4] M. ÇAĞLar, H. Orhan And N. YAĞMUR, Coefficient bounds for new subclasses of bi-univalent functions, Filomat 27, 7 (2013), 1165-1171.

[5] M. Chen, On the regular functions satisfying $\Re(f(z) / z)>\alpha$, Bull. Inst. Math. Acad. Sinica 3, (1975), 65-70.

[6] P. N. Chichra, New subclasses of the class of close-to-convex functions, Proc. Amer. Math. Soc. 62, (1977), 37-43.

[7] S. S. Ding, Y. Ling And G. J. BAO, Some properties of a class of analytic functions, J. Math. Anal. Appl. 195, 1 (1995), 71-81.

[8] E. H. DOHA, The first and second kind Chebyshev coefficients of the moments of the general-order derivative of an infinitely differentiable function, Int. J. Comput. Math. 51, (1994), 21-35.

[9] P. L. Duren, Univalent functions, Grundlehren der Mathematischen Wissenschaften 259, Springer, New York, 1983.

[10] J. DzIOK, R. K. RAInA And J. SoKóŁ, Application of Chebyshev polynomials to classes of analytic functions, C. R. Math. Acad. Sci. Paris 353, 5 (2015), 433-438.

[11] B. A. Frasin And M. K. Aouf, New subclasses of bi-univalent functions, Appl. Math. Lett. 24, 9 (2011), 1569-1573.

[12] T. H. MacGregor, Functions whose derivative has a positive real part, Trans. Amer. Math. Soc. 104, (1962), 532-537.

[13] N. Magesh AND V. PRAMEela, Coefficient estimate problems for certain subclasses of analytic and bi-univalent functions, Afr. Mat. 26, 3 (2013), 465-470.

[14] J. C. MASON, Chebyshev polynomial approximations for the L-membrane eigenvalue problem, SIAM J. Appl. Math. 15, (1967), 172-186.

[15] H. Orhan, N. Magesh And V. K. Balaji, Initial coefficient bounds for a general class of biunivalent functions, Filomat, 29, 6 (2015), 1259-1267.

[16] H. M. Srivastava, A. K. Mishra And P. GochHayat, Certain subclasses of analytic and biunivalent functions, Appl. Math. Lett. 23, 10 (2010), 1188-1192. 
[17] T. Whittaker And G. N. Watson, A course of modern analysis, reprint of the fourth (1927) edition, Cambridge Mathematical Library, Cambridge Univ. Press, Cambridge, 1996.

[18] P. ZAPRAWA, Estimates of initial coefficients for bi-univalent functions, Abstr. Appl. Anal. 2014, Art. ID 357480, 1-6. 